\title{
Características do Pensamento Computacional Desenvolvidas em Aprendizes do Ensino Médio por meio de Atividades Makers
}

\author{
Julia P. Metzger ${ }^{1}$, André L.A. Raabe ${ }^{123}$, André L. M. Santana ${ }^{1}$, Eduardo B. \\ Gomes $^{1}$, Felipe T. de Souza ${ }^{1}$, Gustavo L. Ramos ${ }^{1}$, Larissa A. Cucco ${ }^{1}$, Marli F. V. \\ Vieira ${ }^{24}$ \\ ${ }^{1}$ Laboratório de Inovação Tecnológica na Educação - CTTMar - UNIVALI \\ ${ }^{2}$ Programa de Pós-Graduação em Educação \\ ${ }^{3}$ Mestrado em Computação Aplicada \\ ${ }^{4}$ Instituto Federal de Educação, Ciência, e Tecnologia Catarinense - (IFC) \\ raabe@univali.br, andrelms@univali.br, lite@univali.br, \\ marli.vieiradifc.edu.br
}

\begin{abstract}
The article reports and promove reflections about learning and the potential activities makers for the development of computational thinking. It presents an project, which was reapplied, inspired by constructionist learning and realizes with high school students. The projects developed by the apprentices will be presented, followed by reflections based on the records and observations made in the creation process, aiming to identify different characteristics of Computational Thinking (CSTA, 2016). The results indicate that activities in building environments stimulate characteristics such as problem formulation, identification, analysis and implementation of solutions, generalization and transference for a wide range of problems.

Resumo. $O$ artigo relata e promove reflexões acerca da aprendizagem e do potencial de atividades makers para desenvolver do pensamento computacional. Apresenta um projeto inspirado na aprendizagem construcionista e realizado com estudantes do ensino médio. Serão apresentados os projetos desenvolvidos pelos aprendizes seguidos de reflexões apoiadas nos registros e nas observações realizadas no processo de criação, visando identificar diferentes características do Pensamento Computacional (CSTA, 2016). Os resultados indicam que atividades makers em ambientes construcionistas estimulam características como formulação de problemas, identificação, análise e implementação de soluções, generalização e transferência para outros problemas.
\end{abstract}

\section{Introdução}

A sociedade vivencia mudanças significativas nas mais diversas áreas de atuação, porém o mesmo não ocorre no contexto escolar. Papert (1980) estudioso da aprendizagem construcionista indica que o computador e as novas tecnologias são portadores de ideias pluralistas que mantém a promessa de catalisar mudanças na educação e na cultura em geral.

As tecnologias culturais inseridas em uma sociedade pode contribuir com o aprimoramento de habilidades cognitivas que estimulam de forma criativa, a 
aprendizagem. A abordagem construcionista visa o protagonismo dos aprendizes, já que possibilita que estes usem seus estilos próprios para fazerem o que gostam utilizando objetos culturais inseridos na sociedade, que os levem a pensar sobre o problema a ser solucionado desenvolvendo sua aprendizagem (RAABE, et. al, 2016). Atividades mão na massa - hands-on - empoderam os aprendizes quando trabalham em um ambiente construcionista, instigando habilidades e competências ao criar algo de seu interesse.

Atividades mão na massa estão associadas a cultura maker, a qual o aprendiz combina tecnologias, conhecimentos e computação. Os aprendizes "makers" são motivados a desenvolverem projetos de seu interesse visando solucionar problemas que os levem a alcançar seus objetivos desenvolvendo a própria aprendizagem (MILNE; RIECKE; ANTLE, 2014).

O movimento maker está relacionado a aprendizagem prática, a qual o estudante é protagonista do processo de construção do seu conhecimento, sendo o autor da resolução dos problemas encontrados e do próprio contexto de aprendizagem. $\mathrm{Na}$ aprendizagem prática ocorre a valorização da experiência do aprendiz, permitindo que esse aprenda com seus erros e acertos, com a satisfação em compreender assuntos e temas do seu próprio interesse, que estão relacionados com seu cotidiano (BLIKSTEIN,2009, 2013). Essas ideias proporcionam aprender de maneira criativa e desenvolve o que está sendo chamado de Pensamento Computacional.

A teoria de aprendizagem construcionista pode ser associada ao desenvolvimento do Pensamento Computacional cunhado por Wing (2006). O Pensamento Computacional é pautado em elementos objetivos, que visa o processo de resolução de problemas e que inclui (não somente) as seguintes características: (i) formulação de problemas de forma que tecnologias culturais possam ajudar a resolvê-los; (ii) organização lógica e análise de dados; (iii) identificação, análise e implementação de soluções; (iv) generalização e transferência de soluções para uma ampla gama de problemas (CSTA, 2016).

A aprendizagem prática e o Pensamento Computacional convergem para um ensino que prioriza a criatividade, inventividade e produtividade dos aprendizes, que são protagonistas no desenvolvimento do seu próprio conhecimento. As atividades relatadas nessa experiência visam desenvolver o Pensamento Computacional de forma criativa em um ambiente construcionista, que se baseia no aprendizado prático com raízes na cultura maker, oportunizando aos aprendizes desenvolver suas ideias criando sua própria tecnologia de acordo com seus interesses. O ambiente Maker que essa experiência foi realizada é o Laboratório de Inovação Tecnológica na Educação - Lite ${ }^{1}$.

\section{Materiais e Métodos}

Este trabalho é uma continuidade dos trabalhos apresentados no Artigo intitulado "Atividades Maker no Processo de Criação de Projetos por Estudantes do Ensino Básico para uma Feira de Ciências" apresentado e publicado nos anais do WIE $2016^{2}$.

O Lite é um laboratório de ensino e pesquisa que realiza também projetos de

\footnotetext{
${ }^{1}$ Maiores informações disponível em: $<$ Lite.acad.univali.br/>.

${ }^{2}$ Maiores informações disponíveis em: $<$ http://www.br-ie.org/pub/index.php/wie/article/view/6615>.
} 
VI Congresso Brasileiro de Informática na Educação (CBIE 2017)

Anais do XXIII Workshop de Informática na Escola (WIE 2017)

extensão. O laboratório adota e fomenta a cultura maker nos projetos desenvolvidos pelos seus integrantes e voluntários. O Lite contém equipamentos como impressora 3D, ferramentas de marcenaria, bancada de solda e diversos materiais que permitem a realização de atividades das áreas de eletrônica, artesanato, marcenaria, costura e modelagem.

Desta forma o ambiente promove a convivência de professores de graduação e pós-graduação, estudantes da graduação dos cursos da Ciência da Computação, Engenharia da Computação, Mecânica, Design e Arquitetura, como também pós-graduandos em nível de mestrado e doutorado, das áreas da Computação Aplicada e Educação.

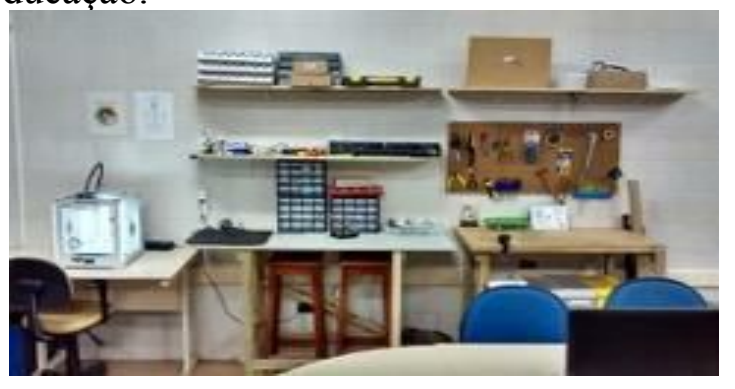

Figura 1 - Algumas das Ferramentas do Lite

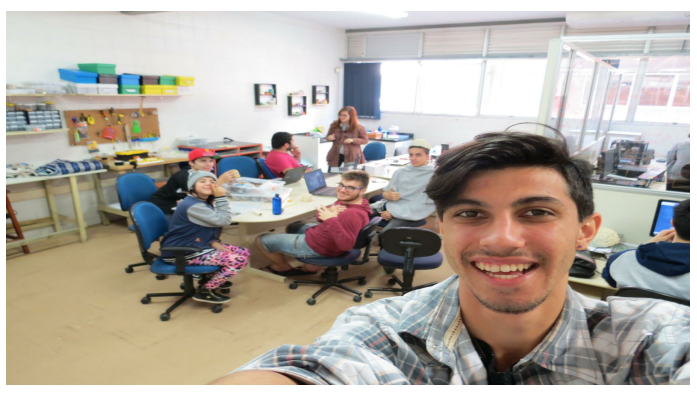

Figura 2 - Computadores e Ambiente Físico

O Lite Is Cool é um projeto de extensão conduzido pelo Laboratório que acontece em parceria com uma escola pública estadual. Este projeto busca proporcionar o desenvolvimento do pensamento colocando os estudantes em contato com conceitos e práticas, que contemplam áreas além da Computação. Os estudantes aprendem conceitos de lógica de programação, desenvolvem pequenas aplicações programando o Portugol Studio (NOSCHANG, 2014), conhecem conceitos de eletrônica e sistemas digitais, desenvolvem projetos de robótica com uso de microcontroladores, Arduíno e linguagem $\mathrm{C}$, além de atividades de marcenaria, costura e artesanato.

Os estudantes que participaram do Lite Is Cool em 2016 foram indicados pela direção da escola Estadual Nereu Ramos, adotando como critério de seleção os estudantes com maior envolvimento em atividades escolares e não mais pelas melhores notas, como ocorreu no ano anterior. Em 2016 o projeto teve a participação de 13 (treze) integrantes sendo estes 9 (nove) meninos e 4 (quarto) meninas. Os estudantes foram divididos em duas turmas, uma formada por 6 (seis) estudantes que participaram do projeto no ano de 2015 e tinham interesse em participar novamente e outra turma por 7 (sete) estudantes selecionados pela escola, que adotou um o novo critério de seleção.

No andamento do projeto dois estudantes, do grupo dos novos estudantes, se desligaram do grupo. com isso tivemos 11 (onze) aprendizes que cursavam o ensino médio. Os encontros aconteciam 2 (duas) vezes por semana para cada turma, com 4 (quatro) horas de duração cada encontro, totalizando em cada turma 8 (oito) horas semanais.

O programa de atividades realizado possibilitou aos participantes vivenciarem os preceitos do construcionismo e do movimento maker que serão detalhados nesse relato de experiência. As atividades iniciaram-se em abril e finalizaram-se em novembro de 2016, neste período os aprendizes desenvolveram projetos pessoais relacionados a algumas das características do Pensamento Computacional. 


\section{Relato da Experiência}

Nessa experiência tivemos atividades diferenciadas para os alunos que haviam participado do Lite Is Cool 2015 em relação aos estudantes que vivenciaram seu primeiro ano de Lite Is Cool em 2016. Nomearemos a turma de veteranos do Lite Is Cool como Turma A e a turma iniciante como Turma B.

Durante as atividades aplicadas foram realizadas paralelamente workshops com o objetivo de aproximar os estudantes das ferramentas contidas no laboratório, ampliando as áreas de conhecimento de fotografia, documentação de projetos e modelagem com biscuit. As técnicas básicas de programação com Arduino e eletrônica foram trabalhas somente com a Turma B.

Visto que Turma A já possuía os conhecimentos iniciais propostos, as atividades para esta turma foi o desenvolvimento de projetos explorando novos conhecimentos nas áreas de fotografia, costura, programação, eletrônica e artesanato. $\mathrm{Na}$ Turma $\mathrm{B}$ as atividades propostas foram construídas com o objetivo de estimular os conhecimentos iniciais propostos em 2015 que eram: conceitos de lógica de programação; construir pequenas aplicações com programação com uso do Portugol Studio; conceitos de eletrônica e sistemas digitais; projetos de robótica com uso de microcontroladores usando Arduíno e linguagem $\mathrm{C}$. O projeto foi remodelado com foco em desafios e foram incluídos os novos conhecimento utilizados também com a Turma A. As duas turmas finalizaram o ano de 2016 desenvolvendo projetos de interesses pessoais.

A Turma A iniciou as atividades explorando a ferramenta mblock $^{3}$, com o objetivo de verificar como os estudantes conseguiriam utilizar o Arduino associado a linguagem em blocos proporcionada por essa ferramenta. $\mathrm{O}$ desafio foi de criarem um projeto de interesse pessoal utilizando o Arduino e qualquer recurso presente no laboratório.

Entre os projetos a Figura 3 demonstra o desenvolvimento de um carrinho controlado por um joystick. Os aprendizes responsáveis pelo projeto exercitaram além dos conhecimentos de lógica de programação, conhecimentos sobre modelagem 3D presentes nas rodas do carrinho que modelaram e imprimiram. Por conta do tempo proposto para a atividade os estudantes não conseguiram finalizar a carcaça do carrinho, porém desenvolveram toda a parte lógica e eletrônica.

A Figura 4 demonstra o projeto de uma caixa musical, que é capaz de tocar 3 tipos de músicas diferentes e rodar um disco. Neste projeto os aprendizes juntaram os conhecimentos prévios, decorrente de interesse pessoal, programando cada uma das notas musicais para recriar músicas de seus interesses, conseguindo completar todo o projeto lógico, eletrônico e físico.

\footnotetext{
${ }^{3}$ Maiores informações disponível em: <http://ite.acad.univali.br/portugol/>.
} 


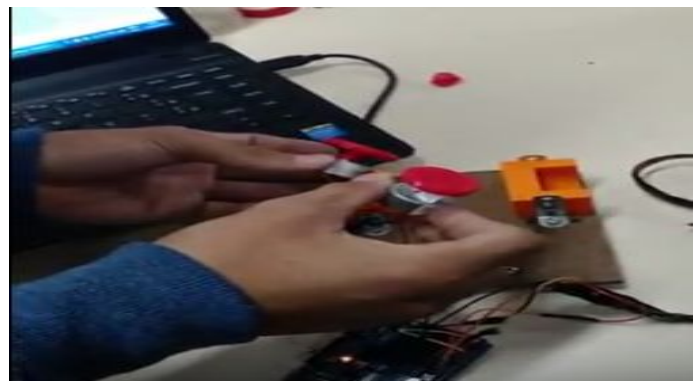

Figura 3 - Criando Projetos - Carrinho

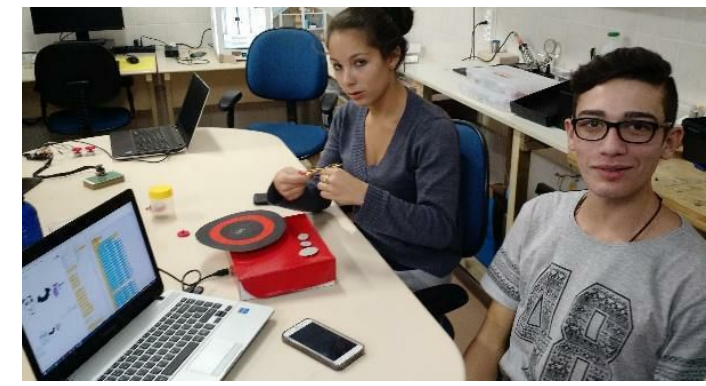

Figura 4 - Criando Projetos - Caixa musical

Associado com um projeto de um Sarau Literário da escola Nereu Ramos, foi desenvolvida a proposta dos estudantes de criarem um jogo ou animação baseado no livro "O Pequeno Príncipe" iriam desenvolver seus projetos, porém todos escolheram o Portugol Studio. Dentre os projetos desenvolvidos um grupo desenvolveu um jogo de plataforma Puzzle, que envolve perguntas relacionadas aos personagens e a história do livro.

As Figuras 5 e 6 demonstram imagens de um dos jogos desenvolvido, no qual o personagem interage com o ambiente tendo que se movimentar, coletando bônus pelo caminho e desviando de obstáculos até o ponto de chegada. Esta atividade proporcionou uma interação entre a escola Nereu Ramos e o Lite, já que os integrantes do laboratório foram convidados a assistir as apresentações do Sarau Literário.

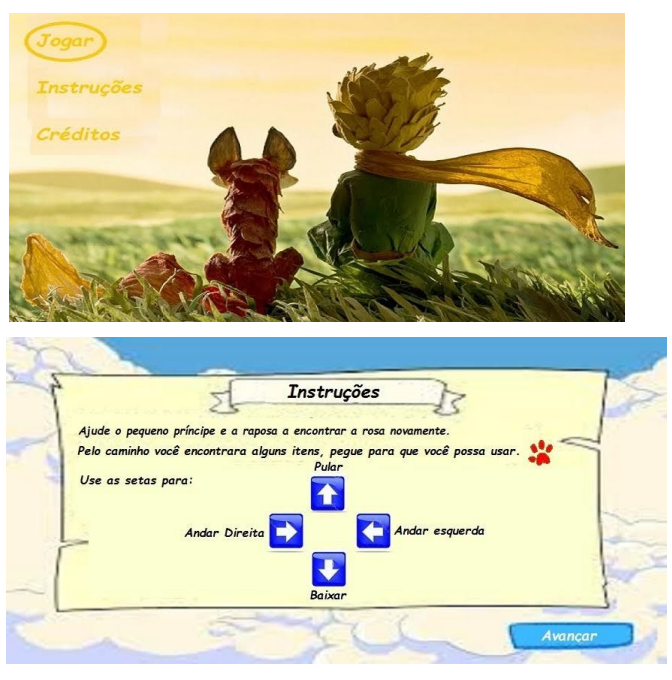

Figura 5 - Jogo Baseado Pequeno Príncipe
Figura 6 - Instruções do Jogo

A última atividade proposta foi para que os aprendizes criassem projetos de interesse pessoal escolhendo qualquer recurso presente no Lite. Durante o processo de desenvolvimento dos projetos se depararam com o uso de tecnologias já estudadas previamente, porém ao desenvolver seus projetos pessoais se depararam com desafios nunca vivenciados. No total foram desenvolvidos 3 (três) projetos diferentes, objetivando trabalhar de forma colaborativa compartilhando ideias e opiniões entre os grupos.

Um dos grupos decidiu fazer uma chocadeira de ovos inteligente, já que um dos

\footnotetext{
${ }^{4}$ Esse livro foi escrito por Antoine de Saint-Exupéry em 1943.
} 
aprendizes tinha criado uma chocadeira de ovos, porém percebeu que nem todos os ovos eclodiram. Então planejaram aquecer os ovos e monitorar a temperatura e umidade do ambiente onde os ovos seriam colocados. Para isso utilizaram conhecimentos de eletrônica e programação. Além disso utilizaram os conhecimentos de artesanato para criar a estrutura da chocadeira e muitas pesquisas para entender os aspectos biológicos do processo de chocar um ovo. Ao final deste projeto os estudantes não obtiveram sucesso no aquecimento da chocadeira, pesquisaram vários componentes eletrônicos e fizeram vários testes, porém por conta do tempo não conseguiram finalizá-lo por completo.

Outro projeto foi de um carregador de celular, o qual tinha o objetivo de carregar um celular utilizando uma bateria de 9 volts. Este projeto envolveu os conhecimentos de eletrônica e impressão 3D, para a criação da carcaça do carregador. Exercitaram suas habilidades de pesquisa para encontrar as informações sobre os componentes eletrônicos desconhecidos. Ao final do projeto os estudantes obtiveram sucesso, porém o mesmo deixou de funcionar pouco tempo depois, por conta da finalização das atividades deste ano não conseguiram solucionar o problema.

O último grupo desenvolveu um jogo na ferramenta Portugol Studio, o jogo ilustra o funcionamento do RoPE ${ }^{5}$ - Robô Programável Educacional, um projeto também criado no Lite. Nesse jogo o objetivo é programar o RoPE para chegar em um determinado local. Os estudantes exercitaram conhecimentos de programação obtendo sucesso, um dos integrantes mencionou que gostaria de evoluir o jogo.

As atividades da Turma B começou por meio do jogo "Programe ao Paulo", e posteriormente com jogos de programar como: Nobugs snackbar ; Light Bot ${ }^{7}$ e o Code Combat ${ }^{9}$. Essa estratégia serviu para aproximá-los das ideias que envolvem a atividade de programação.

Para envolver os aprendizes com os projetos presentes no laboratório, eles foram convidados a desenvolver uma atividade para o RoPE, criando uma história, um tapete temático e as regras da brincadeira. A Figura 7 e 8 demonstram a atividade, que além das habilidades proporcionadas pelo brinquedo RoPE, habilidades como trabalho em equipe, planejamento e criatividade se demonstraram indispensáveis para o sucesso.

\footnotetext{
${ }^{5}$ Maiores informações disponível em: <http://lite.acad.univali.br/pt/projetos/brinquedo-de-programar/>

${ }^{6}$ Esse jogo foi criado com o intuito de realizar atividades de introdução à programação. Jogo detalhado no Trabalho de Conclusão de Curso do Curso de Engenharia da Produção da UNIVALI por Rodrigo Ramos Martins intitulado de: Desenvolvimento de Uma Metodologia para explorar habilidades de engenharia através do uso de Brinquedos Programáveis. Trabalho em fase final de conclusão, não estando ainda disponível na Internet.

${ }^{7}$ Disponível em: <http://nobugssnackbar.dei.uc.pt/>.

${ }^{8}$ Disponível em: $<$ https://lightbot.com/>.

${ }^{9}$ Disponível em: < http://br.codecombat.com/>.
} 
VI Congresso Brasileiro de Informática na Educação (CBIE 2017)

Anais do XXIII Workshop de Informática na Escola (WIE 2017)

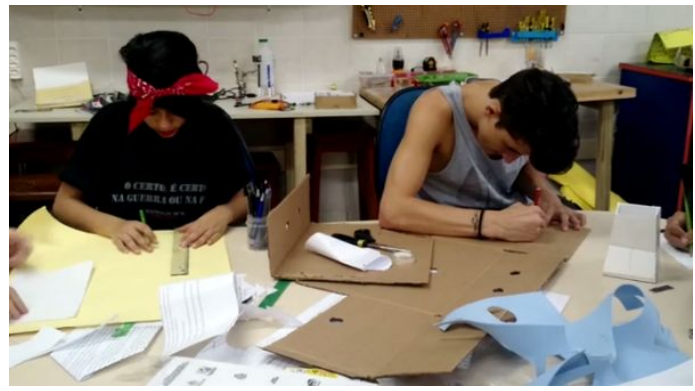

Figura 7 - Tapete do RoPE

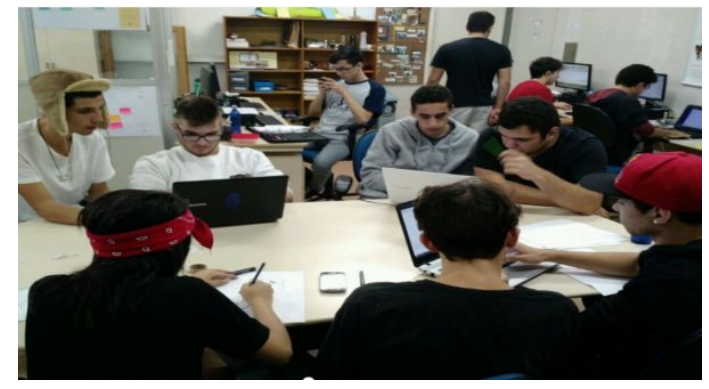

Figura 8 - Programação - Turma B

Os aprendizes da Turma B tiveram seu primeiro contato com programação textual por meio da ferramenta Portugol Studio (Figura 8), nessa atividade foram propostos alguns desafios começando pelos mais básicos, como escrever frases e entender o conceito de variável, explorando os diferentes tipos. Alguns estudantes se identificaram com a programação e solucionaram os desafios com facilidade.

Já que nem todos os aprendizes desta turma se identificaram com o estudo de programação, foi proposta uma atividade para criar roupas com os materiais disponíveis no Lite. Um grupo ficou responsável de criar um programa, no qual o usuário informa suas medidas, a peça de roupa desejada e o programa gera uma imagem com os cortes e medidas do tecido. Outro grupo ficou responsável pela confecção das roupas e outro pela criação de uma marca que as representariam. Antes de iniciar a atividade foi realizada uma conversa com os estudantes abordando tópicos como estilos de roupas, mensagens que as roupas passam e como as roupas podem influenciar o estado emocional das pessoas. Desta forma, ocorreu uma integração entre os grupos.

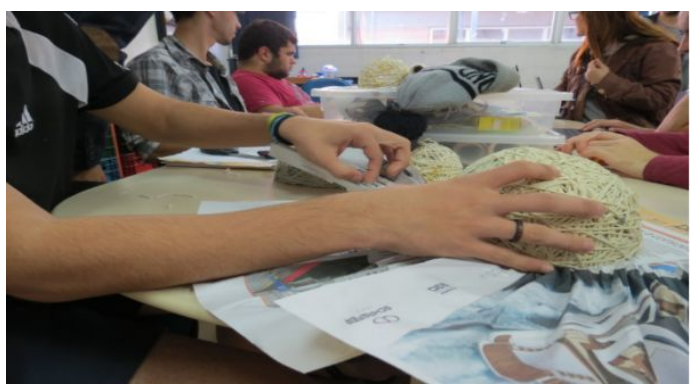

Figura 9 - Confecção de Roupas

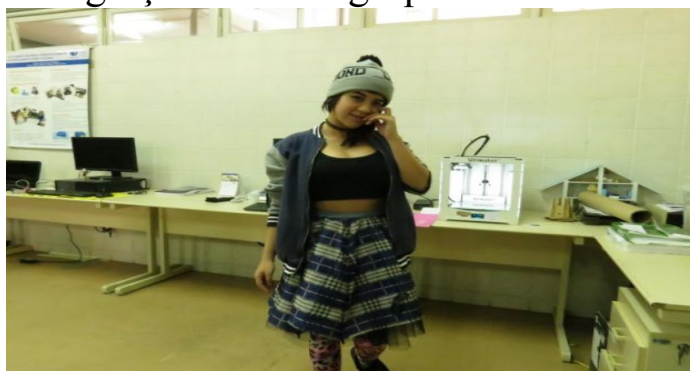

Figura 10 - Saia de Guarda Chuva

Uma das estudantes compartilhou com o grupo uma saia feita com o tecido de um guarda-chuva quebrado que ela e sua mãe confeccionaram para um desfile de roupas recicláveis que aconteceu na Escola Nereu Ramos (Figura 10). Além da saia, a estudante compartilhou informações e materiais usados por sua mãe, enriquecendo ainda mais a atividade proposta.

Assim como na Turma A, a Turma B também desenvolveu projetos de interesses pessoais que envolveram conhecimentos adquiridos anteriormente por meio das atividades realizadas. No total foram desenvolvidos 4 (quatro) projetos diferentes.

Um dos estudantes teve a ideia de criar um capacete que imitasse o do "Homem de Ferro", a princípio o objetivo era construir o capacete e utilizar os conhecimentos de eletrônica, adquiridos em um dos Workshops, para iluminar e um motor para abrir o 
capacete automaticamente. Por conta do tempo para execução do projeto o estudante não conseguiu desenvolver a parte eletrônica, mas construiu a estrutura física do capacete.

Um grupo de estudantes encontrou na internet um projeto de um tênis que acende luzes quando pisa, eles ficaram encantados com a ideia e decidiram tentar criar sua própria versão. $\mathrm{O}$ grupo teve bastante dificuldade para entender a parte eletrônica não conseguindo completá-lo, porém eles aprenderam muito sobre eletrônica e construíram vários protótipos para teste.

Outro aprendiz tinha bastante interesse por música e decidiu fazer uma guitarra elétrica a partir de um violão velho. $\mathrm{O}$ estudante passou bastante tempo trabalhando na carcaça de seu projeto (Figura 11), transformando o violão em uma guitarra, e acabou por não fazer a parte eletrônica do projeto.

O interesse pela programação foi demonstrado por um estudante que resolveu criar um jogo (Figura 12) como seu projeto de final de ano. Optou por utilizar uma ferramenta diferente das vistas anteriormente e desta forma explorou ainda mais as estratégias contidas no ato de programar. $\mathrm{O}$ estudante demonstrou-se motivado no decorrer dessa atividade e ao final criou um jogo de plataforma, no qual o personagem protagonista é capaz de correr, pular, desviar de obstáculos e atirar.

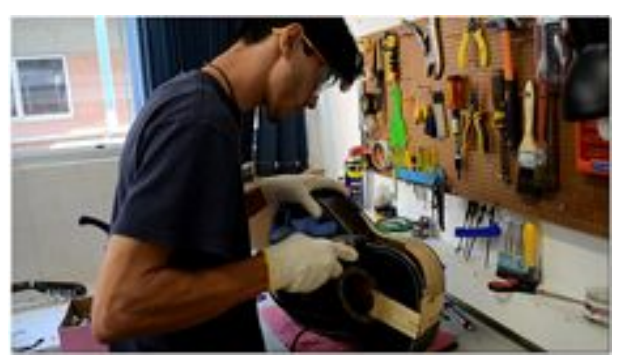

Figura 11 - Criando uma Guitarra

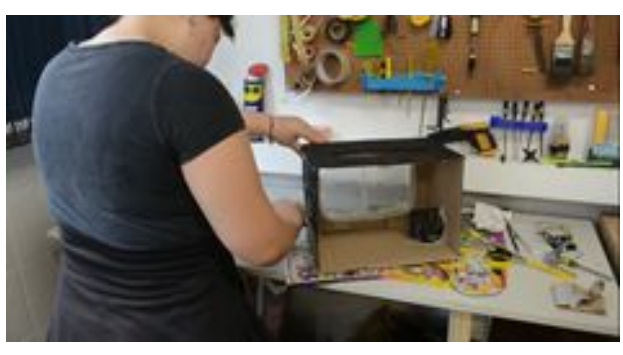

Figura 12 - Criando uma Chocadeira

O ambiente proporcionado no Lite visa exercitar o desenvolvimento de projetos de forma colaborativa, cooperativa e compartilhada. Nas atividades desenvolvidas no Lite Is Cool estimulou-se o envolvimento de aspectos como respeito por diferentes opiniões, compartilhamento de ferramentas, repasse de informações e valorização de habilidades específicas de cada estudante, obteve-se resultados positivo em relação a esses aspectos.

\section{Conclusões}

A presença e aproximação dos aprendizes com tecnologias culturais nos projetos desenvolvidos possibilitaram a construção dos projetos pessoais e resolução dos desafios propostos nas atividades do Lite Is Cool.

Outra característica indicada pelo CSTA é a organização lógica e análise de dados as quais estiveram presentes de forma mais evidente na etapa de criação de projetos pessoais. A medida que os estudantes definiram seus projetos, precisavam planejar as etapas a serem executadas para alcançar êxito em suas criações. Observou-se 
que os projetos que tinham pouca ou nenhuma documentação na etapa de planejamento, foram os mesmos que tiveram maiores dificuldades de concluir o projeto.

O projeto Lite Is Cool estimulou a pesquisa por parte dos aprendizes, para que desta forma encontrassem soluções para um desafio proposto ou para execução de um projeto. A ausência de alguns materiais e tecnologias no Lite levaram os aprendizes a implementar soluções modificadas, em relação aos originais, para adaptar aos recursos presentes no laboratório.

A característica de generalização e transferência de soluções esteve presente no Lite Is Cool em diversos momentos por conta do laboratório conduzir aprendizagens construcionista permitindo que os estudantes atuem como protagonistas em seu processo de conhecimento, explorando diversos recursos. Esse tipo de ambiente propiciou aos estudantes conheceram novas tecnologias, reaplicando os conhecimentos adquiridos na criação de novos projetos.

A diferença entre os gêneros não foi evidenciada nas atividades com o Lite Is Cool já que tanto meninos quanto meninas não demonstraram nenhum tipo de preconceito em relação às mais diferenciadas tecnologias existentes no Lite.

Os projetos e atividades realizadas foram marcadas pelas características pessoais ou dos grupos que as executaram, nos quais evidenciaram-se os gostos particulares dos envolvidos, evidenciando $\mathrm{o}$ protagonismo presentes nas prerrogativas do construcionismo e do movimento Maker.

A presença de um ambiente repleto de tecnologias com integrantes, de pós-graduação e ensino superior, que conhecem diversas áreas do conhecimento e dominam diversas tecnologias, estimulou os aprendizes a não imporem limites às suas criações. $\mathrm{O}$ ambiente construcionista possibilitou explorar habilidades inventivas e produtivas, tornando os aprendizes protagonistas na resolução de problemas e no desenvolvimento do seu próprio conhecimento.

Espera-se que atividades como essa possam servir de inspiração para proporcionar o desenvolvimento do pensamento computacional em atividades makers que seguem pressupostos construcionistas.

\section{Referências}

Blikstein, P.( 2013) Digital fabrication and 'making'in education: The democratization of invention. FabLabs: Of machines, makers and inventors", p. 1-21.

. (2009) You cannot think about thinking without thinking about what Seymour Papert would think.

CSTA. Computer Science Teachers Association (Org.).(2011) "Operational Definition of Computational Thinking:” for K-12 Education. Disponível em: Acesso em: 19/08/2016.

Milne, A.; Riecke, B.; Antle, A. (2014) Exploring Maker Practice: Common Attitudes, Habits and Skills from Vancouver's Maker Community. Studies, v. 19, n. 21. p. 23.

Papert, S. (1980) Mindstorms: Children, computers and powerful ideas. Basic Books, 
VI Congresso Brasileiro de Informática na Educação (CBIE 2017)

Anais do XXIII Workshop de Informática na Escola (WIE 2017)

$n c$. Artes Médicas: Porto Alegre.

Raabe, André L. A, et al. (2016) “Atividades Maker no Processo de Criação de Projetos por Estudantes do Ensino Básico para uma Feira de Ciências". In: Anais do Workshop de Informática na Escola. p. 181.

Wing, J. M. (2006). Computational thinking. Communications of the ACM, 49(3), 33-35. 